\title{
On the Temperature Dependence of Self-Diffusion in Alpha Iron
}

\author{
by I. D. Bakalar
}

\begin{abstract}
A SELF-DIFFUSION study in iron has been underway at M.I.T. for several years. Part of the results reported at the Sylvania Conference on "The Physics of Sintering" gave the diffusion equation $D_{x}=5.8 \mathrm{e}^{\frac{-5.38 .7 m 1}{\mathrm{HT}}}$ (1) as holding between $809^{\circ} \mathrm{C}$ and $905^{\circ} \mathrm{C}$. This equation has turned out to be in serlous conflict with the $\mathrm{D} \alpha=2.3 \times 10^{\mathrm{e}} \mathrm{e}^{\frac{-73.290}{\mathrm{RT}}}(2)$ later reported by Birchenall and Mehl. ${ }^{2}$ It was felt that a check could best be made upon the reported equations by carrying out some diffusion runs in the $\delta$ region where the dffusion values predicted by (1) and (2) differ by more than 600 pct. Such runs have verified that equation (1) holds in the $\alpha$ and $\delta$ regions for temperatures greater than $800^{\circ} \mathrm{C}$.
\end{abstract}

I. D. Bakalar is with the Metallurgy Dept., Massachusetts Institute of Technology, Cambridge, Mass.
The low temperature work of Birchenall and Mehl has also indicated that the $\log \mathrm{D}$ vs. $\frac{1}{\mathrm{~T}}$ plot for the $\alpha$ iron curves downwards somewhere below $800^{\circ} \mathrm{C}$. It was impossible to check this possible curvature with the standard surfacedecrease specimens $\left(2 \times 10^{-3} \mathrm{~cm}\right.$ plate thickness) because of low sensitivity. Attempts were therefore made to use a thinner radioactive plate such as adopted by Birchenall and Mehl. Results were obtained which indicated curvature but had to be considered unreliable because of large anomalous scatter. It was felt that this scatter might be due to surface diffusion. A new "surface increase" specimen was therefore devised to overcome this possibility. At the present time further runs are underway and results will be available for the October Meeting.

1 Bayside, Long Island, August 24-26, 1949.

2 Journal of Metals, January, 1950, p. 144.

\section{Effect of Uniaxial Compressive Stresses on Self-Diffusion in Alpha Iron}

\author{
by F. S. Buffington
}

$\mathrm{T}$ HE effects of uniaxial compressive stresses on self-diffusion rates in pure iron are being studied at temperatures high in the alpha range. The diffusion specimen is of the surface-decrease type, formed by plating radioactive iron on one face of a disc of inert iron. A quartz disc is placed directly against the electroplated layer and a load applied on the quartz to stress the specimen in simple compression.

This method has several advantages over other possible ones in that:

(1) The sensitive surface-decrease method permits short diffusion runs with little distortion and little change in cross-sectional area of the specimen.

(2) Any distortion which does occur is uniform within the diffusion zone, so that boundary conditions are maintained.

(3) The quartz disc in intimate contact with the plated face minimizes the loss of ra- dioactive iron in the vapor phase, again maintaining boundary conditions.

(4) The stress system within the specimen is simple, so that no complications occur in determining the existing true stress.

(5) Analysis of results is rapid, requiring only a few hours.

A possible disadvantage of the method is that the interdiffusion between quartz and iron and loss of radioactive iron as vapor may give erroneously high $\mathrm{D}$ values. However, it was found that this method gives a $D$ value less than 50 pet higher than the correct value at $885^{\circ} \mathrm{C}$ for unstressed specimens. It is possible to correct for this error, since it is a systematic discrepancy.

F. S. Buffington is associated with Massachusetts Institute of Technology, Cambridge, Mass. 